\title{
PRONUNCIAMIENTO DE LA RED DE CENTROS SOCIALES DE LA COMPAÑÍA DE JESÚS EN AMÉRICA LATINA Y EL CARIBE
}

\section{Sobre la oleada de protesta social y las frágiles democracias de nuestro continente}

Diciembre de 2019

\begin{abstract}
«No hay democracia con hambre, ni desarrollo con pobreza, ni justicia en la inequidad. Un sistema político-económico, para su sanodesarrollo, necesitagarantizarque la democracianoseasólo nominal, sino que pueda verse plasmada en acciones concretas que velen por la dignidad de todos sus habitantes bajo la lógica del bien común, la solidaridad y uma opción preferencial por los pobres».
\end{abstract}

Papa Francisco durante la Cumbre Panamericana de Jueces sobre Derechos Sociales y Doctrina Franciscana, junio 2019.

Latinoamérica ha estado viviendo durante este segundo semestre del 2019 un estado de ebullición social, política y económica. En los últimos meses, las democracias del continente y sus aparatos estatales han mostrado sus grandes limitaciones y sombras, como las violaciones sistemáticas a los Derechos Humanos, la adopción de medidas que fomentan la destrucción de las economías locales y el impacto negativo de los megaproyectos minero energéticos sobre los territorios y los patrimonios naturales y culturales. A la par, se vive una oleada de movilizaciones que expresan el deseo de los pueblos a no resignarse a una dinámica histórica de exclusión. Las calles Latinoamericanas evidencian el grito de una ciudadanía agotada por la explotacióny la convergencia de diversas formas de resistencia.

Para la mayoría de la población, el desempleo, los bajos ingresos económicos, el acceso limitado y precario a la salud, la baja calidad de la educación, la inequidad en los sistemas pensionales, la inseguridad, la represión política sobre las propuestas y resistencias de los pueblos, la corrupción y el deterioro de lo público, entre otras problemáticas, son manifestaciones de la fragilidad de los sistemas políticos en Latinoamérica. Estas situaciones provocan una acelerada migración de millones de personas, sobre todo de jóvenes, en búsqueda de alternativas para sobrevivir.

En este contexto, tienen lugar las protestas de millones de personas y organizaciones a lo largo yancho del continente, provenientes de diversos sectores, en su mayoría populares: los pueblos indígenas y las comunidades afrodescendientes y campesinas, las mujeres, los

Cadernos do CEAS, Salvador/Recife, n. 248, p. 788-791, set./dez., 2019 | ISSN 2447-861X | doi>: http://dx.doi.org/10.25247/2447-861X.2019.n248.p788-791 
estudiantes y los maestros, los sindicatos, a quienes cada día se unenjóvenes inconformes que consideran que las medidas de política social y económica los perjudican de manera grave y los deja sin futuro, pues reducen cada vez más las oportunidades de accedera la educación superior, a un trabajo digno y a un desarrollo.

Así ocurrió en Ecuador donde al eliminar el subsidio a los combustibles se reactivaron las movilizaciones de los indígenas y de otros sectores. En Chile, considerado hasta ahora el modelo a seguir, solo bastó aumentar el valor del pasaje del metro de Santiago para que la copa se terminara rebosando. En Brasil se observa cómo la reanudación de proyectos económicos ultraliberales desmantela las estructuras de participación ciudadana, degradan los derechos sociales adquiridos y mercantilizan la naturaleza. Perú vive una crisis institucional y, en Uruguay, la gente protestó masivamente contra el mayor protagonismo de los militares en la vida pública y política del país. Venezuela continúa sacudida por una crisis política, económica, social y humanitaria y, en Bolivia, tras la salida de Evo Morales, el pueblo boliviano se enfrenta a una crisis democrática que refleja problemas políticos y sociales de hondas raíces.

En Centro América y el Caribe tampoco están exentos de padecer injusticia socioambientaly lassecuelas dehistóricasy múltiplesviolencias. Por ejemplo, en Haití, República Dominicana, Nicaragua, Guatemala, Honduras y Panamá se han vivido durante los últimos meses, movilizaciones populares cada día más fuertes y continuas en exigencia de sus derechos.

Recientemente, en Colombia el Paro Nacional que inició el jueves 21 de noviembre y la forma como el Gobierno Nacional ha respondido, muestra el meollo del problema que enfrenta este país y, en general, los países de la región: sociedades marcadas por profundas desigualdades, inequidad y exclusión económica y política, así como sistemas políticos y económicos clientelistas y corruptos.

Si bien los detonantes de las reacciones sociales se manifiestan de manera diferente en este convulsionado continente, hay elementos que tenemos en común: la indignacióny el descontento causados por la desconexión de las élites políticas y económicas con las realidades de las grandes mayorías; esta es la crisis de un modelo de Estado puesto al servicio de grupos económicos con enorme capacidad de influir en el diseño de políticas públicas que generan pobreza, y de grupos políticos aferrados al poder con modelos igualmente excluyentes. Desde la perspectiva de Boaventura De Sousa, asistimos a la implantación de un 
cierto fascismo pluralista que antes no había existido, en el cual las sociedades son políticamente democráticas y socialmente fascistas ${ }^{11}$.

Por todo lo anterior, la Red de Centros Sociales de la Compañía de Jesús en América Latina y el Caribe:

Invita a todos los actores sociales y políticos a generar herramientas útiles para reconfigurar las democracias en nuestros países y profundizar la construcción de alternativas efectivas de participación popular. Es necesario implementar nuevas prácticas para la construcción ciudadana de lo público, e iniciativas de diálogo entre los diversos sectores, incluso entre los antagónicos.

Declara su solidaridad con todas las víctimas de la violencia en los diferentes países, rechazamos el hostigamiento a los líderes estudiantiles y sociales, los desmanes y arbitrariedades de la fuerza pública y hacemos un llamado contundente a la garantía de los derechos fundamentales porparte de los gobiernos de nuestros pueblos latinoamericanos.

Reclama a los actuales gobiernos Latinoamericanos crear espacios de diálogo democrático, incluyente y eficaz, a escuchar los clamores ciudadanos y brindar prontas respuestas políticas.

Anima a quienes lideran las movilizaciones a optar por un ejercicio pacífico del derecho a la protesta. Es necesario promover diálogos nacionales incluyentes y brindar las garantías que permitan hacer de la masiva protesta social una oportunidad de reconciliación, de cambio profundo, creativo y no violento, para repensar el rumbo de nuestras naciones y ahondarlas democracias latinoamericanas.

Con fe y esperanza motivamos a que se escuchen los clamores de las gentes, pese a que algunas fuerzas quieren conservar sus grandes privilegios e insisten en aferrarse a salidas violentas. Es tiempo para que juntos encontremos un nuevo modo de organizar nuestra sociedad y nuestra economía, para que se ponga en el centro de sus prioridades al ser humano y a la naturaleza.

La Iglesia, en la voz del santo Pontífice Juan Pablo II, nos interpeló hace ya tres décadas en la encíclica Centesimus Annus: "La Iglesia aprecia el sistema de la democracia, en la medida en que asegura la participación de los ciudadanos en las opciones políticas y garantiza a los gobernados la

\footnotetext{
1 SOUSA SANTOS, Boaventura (2014). Democracia al borde del caos. Ensayo contra la autoflagelación. Bogotá. Siglo
} del Hombre Editores, p. 145. 
posibilidad de elegir y controlar a sus propios gobernantes, o bien la de sustituirlos oportunamentede manera pacífica" (No. 46). 